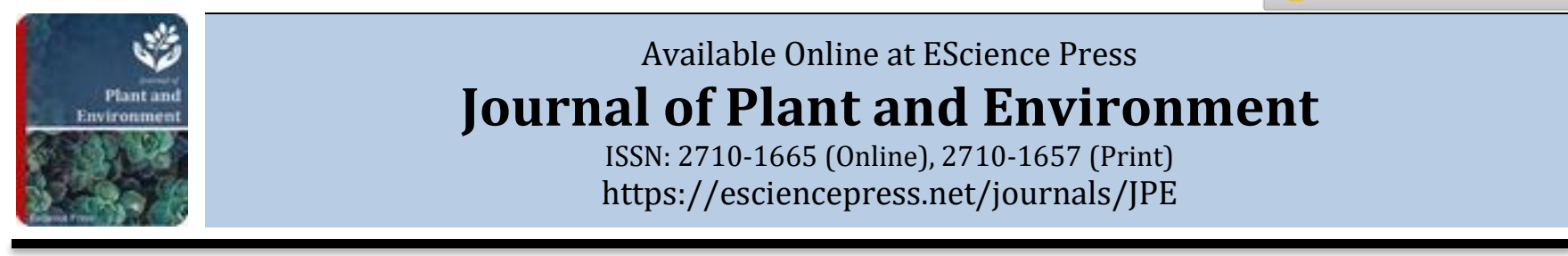

\title{
Covid-19 Treatment with Herbal Medicines: Dark Room can be Enlightened in other Way too
}

\author{
Ali Noman ${ }^{*}$, Muhammad Aqeel ${ }^{2}$, Noreen Akhter ${ }^{3}$, Saad Zafar ${ }^{4}$, Noreen Khalid ${ }^{5 *}$ \\ ${ }^{1}$ Faculty of Life Sciences, Department of Botany, Government college university, Faisalabad, Pakistan. \\ ${ }^{2}$ School of Life Sciences, Lanzhou University, Lanzhou. Gansu, PR China. \\ ${ }^{3}$ Department of Botany, Govt. College Women University, Faisalabad, Pakistan. \\ ${ }^{4}$ District Headquarters Hospital, Faisalabad, Pakistan. \\ ${ }^{5}$ Department of Botany, Government College Women University Sialkot, Sialkot, Pakistan.
}

The author (AN) was infected by Covid-19 and recovered well. His treatment included herbal medicines that lead him to search relevant information and present this opinion.

The start of the year 2020 coupled with Covid-19 (Coronavirus Disease 2019) has utterly changed the attention of the world. Till last year, all were focusing upon trade, media, natural resources, wars, hunger etc. but now all are discussing methods to keep themselves safe from Covid-19. Starting from Wuhan in China, Covid-19 has now spread across the globe. The most important is the issue of non-availability of specific medicine/antivirals/vaccines for this lethal disease and current amelioration procedures only include supportive and non-specific treatment. So far, the arena of herbal medicines for treating Covid-19 patients is totally neglected and all focus is upon preparation of synthetic drugs and vaccines from non-plant resources. The naturally occurring herbal medicines are in use to treat patients with different diseases. Herbal medicines in China had been successfully used for treatment of SARS and MERS, the resembling syndrome to Covid-19 (Organization, 2004; Yang et al., 2020), and it can be particularly fruitful in the scenario of ongoing epidemic. Herbal medicines are a part of clinical support to patients of Covid-19 infection in China (Li and De Clercq, 2020). The in hand data strongly recommends use of herbal medicines as viable option for treating Covid-19 patients across the world. Although different antivirals, antibiotics and corticosteroids i.e. ribavirin, ritonavir, lopinavir, Chloroquine, Amoxicillin, Methylprednisolone etc. are being used for treatment of infected persons but their side effects have highlighted many points to ponder along with careful dosage administration, patient sensitivity and disease stage. For example, the use of Chloroquine has increased the mortality rate in Pakistan. Similarly, ribavirin usage has been noticed responsible for anemia (Jordan et al., 2018). Therefore, we direly need more precise and less harmful treatment options. In our opinion, an integrated line of action with more effectiveness and safety i.e. clinical trials of individual herbal medicines and their combination with different drugs can be doable strategy. Our opinion gets advocacy by the recommendation of Liu et al. (2012) stating positive role of herbs in managing SARS infection by improving symptoms and absorption of pulmonary infiltration as well as absence of any severe event during treatment. Recently, 46 active ingredients from traditional Chinese medicine (TCM) were evaluated for their action against coronavirus S-proteinbinding site of human ACE2 protein and seven herbs principally Lonicerae Japonicae Flos and Mori Folium were attributed with desired activity.

\section{Article History}

Received: May 16, 2020

Revised: June 18, 2020

Accepted: June 25, 2020
Corresponding Author: Ali Noman and Noreen Khalid

Email: alinoman@gcuf.edu.pk; noreen.khalid@gcwus.edu.pk

(C) The Author(s) 2020. 
The results were verified and rationalized by the clinical experiments (Niu et al., 2020). This research innovatively integrated and proved combination of TCM and modern medicine symptomatic therapy comprehensively effective than symptomatic supportive care treatments alone. Similarly, glycyrrhizin from Liquorice root inhibited the replication of SARS virus (Cinatl et al., 2003). Corroborating the facts to make our stance robust, Baicalin (Scutellaria baicalensis) (Schwarz et al., 2014), Quercetin (Toona sinensis Roem) (Chen et al., 2008), luteolin (Veronicalina riifolia) (Yi et al., 2004), that had already been proved for their activity against binding of SARS-S protein with human receptor are potential candidate compounds to be clinically trialed against Covid-19. The helicase protein can also be reckoned as possible anti-HCoV (human coronavirus) target. Due to homology between SARS and nHCoV, these treatment options can be potent weapons in fighting Covid-19. The critical analysis of previous reports and ongoing research strongly favors our opinion and recommend evaluation of different plant-based compounds for their role in treatment and prevention of $\mathrm{CoV}$ infection. Unluckily, herbal medicines are neither fully evaluated nor used potentially for treatment of Covid-19 infection despite their immense benefits and least side effects. Although developed countries like USA and China have allocated and spent billions dollars on research involving herbal medicines for different diseases yet developing as well as under developed countries must come ahead to contribute in herbal medicine research for tackling challenge of Covid-19. Traditional herbal medicines and novel chemical compounds are not only support to global health system but also to deteriorated economy. Investment in herbal medicines is still comparatively small in comparison with overall pharmaceutical business. This is right time to take up gauntlet and start work. Lack of facilities, improper surveillance and low health budgets and non-adoption of preventive measures is already aggravating the situation in many parts of the world. After few months, we can be in a more difficult phase and economic crunch. In parallel with development of plant-based drugs, comprehensive set of ethical issues in this research will be warranted that will definitely help for evaluation of drug validity, toxicological features, socio-medical acceptance and related challenges in designing plant-based drugs that had not been previously addressed. We pertinently mention to appraise the safety of plant-based compounds for treating CoV infections. The herb-drug interaction(s) must be very carefully assessed to prevent toxicity or interference in drug efficacy. A pragmatic and comprehensive scientific framework for herbal medicine research internationally is expected to have positive implications for future research not only in medicinal research but also in social sciences.

\section{REFERENCES}

Chen, C.J., M. Michaelis, H.K. Hsu, C.C. Tsai, K.D. Yang, Y.C. Wu, J. Cinatl Jr and H.W. Doerr. 2008. Toona sinensis Roem tender leaf extract inhibits SARS coronavirus replication. Journal of ethnopharmacology, 120(1): 108-111.

Cinatl, J., B. Morgenstern, G. Bauer, P. Chandra, H. Rabenau and h.W. Doerr. 2003. Glycyrrhizin, an active component of liquorice roots, and replication of SARS-associated coronavirus. The Lancet, 361(9374): 2045-2046.

Jordan, P.C., S.K. Stevens and J. Deval. 2018. Nucleosides for the treatment of respiratory RNA virus infections. Antiviral Chemistry and Chemotherapy. 26: 2040206618764483.

Li, G. and E. De Clercq. 2020. Therapeutic options for the 2019 novel coronavirus (2019-nCoV). Nature Publishing Group; 2020.

Liu, X., M. Zhang, L. He and Y. Li. 2012. Chinese herbs combined with Western medicine for severe acute respiratory syndrome (SARS). Cochrane Database of Systematic Reviews, (10).

Niu, M., R.L. Wang, Z.X. Wang, P. Zhang, Z.F. Bai, J. Jing, Y.M. Guo, X. Zhao, X.Y. Zhan, Z.T. Zhang and X.A. Song. 2020. Rapid establishment of traditional Chinese medicine prevention and treatment of 2019-nCoV based on clinical experience and molecular docking]. Zhongguo Zhong yao za zhi = Zhongguo zhongyao zazhi $=$ China journal of Chinese materia medica, 45(6): 1213-8.

Organization, W.H. SARS: Clinical Trials on Treatment Using a Combination of Traditional Chinese Medicine and Western Medicine. WHO, Geneva, Switzerland. 1-191.

Schwarz, S., D. Sauter, K. Wang, R. Zhang, B. Sun, A. Karioti, A.R. Bilia, T. Efferth and W. Schwarz. 2014. Kaempferol derivatives as antiviral drugs against the 3 a channel protein of coronavirus. Planta medica, 80(02/03): 177-82. 
Yang, Y., M.S. Islam, J. Wang, Y. Li and X. Chen. 2020. Traditional Chinese Medicine in the Treatment of Patients Infected with 2019-New Coronavirus (SARS-CoV-2): A Review and Perspective. International Journal of Biological Sciences, 16(10): 1708-17.

Yi, L., Z. Li, K. Yuan, X. Qu, J. Chen, G. Wang, H. Zhang, H. Luo, L. Zhu, P. Jiang and L. Chen. 2004. Small molecules blocking the entry of severe acute respiratory syndrome coronavirus into host cells. Journal of virology, 78(20): 11334-9.

\section{CONFLICT OF INTEREST}

The authors declare that they have no conflicts of interest.

\section{AUTHORS CONTRIBUTIONS}

AN: Conceived tha idea; AN \& MA: Writing, Review, Editing; NA \& SA: Resources, gathered literature, NK: Critically revised; All authors approved the final version.

Publisher's note: EScience Press remains neutral with regard to jurisdictional claims in published maps and institutional affiliations.

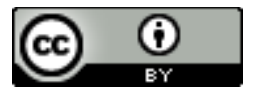

Open Access This article is licensed under a Creative Commons Attribution 4.0 International License, which permits use, sharing, adaptation, distribution and reproduction in any medium or format, as long as you give appropriate credit to the original author(s) and the source, provide a link to the Creative Commons license and indicate if changes were made. The images or other third-party material in this article are included in the article's Creative Commons license, unless indicated otherwise in a credit line to the material. If material is not included in the article's Creative Commons license and your intended use is not permitted by statutory regulation or exceeds the permitted use, you will need to obtain permission directly from the copyright holder. To view a copy of this license, visit http://creativecommons.org/licenses/by/4.0/. 